\title{
Molecular Genetics: Applications in Small and Tree Fruits: Where Is it Working?-Introduction to the Workshop
}

\author{
Chad E. Finn ${ }^{1}$ \\ U.S. Department of Agriculture-Agricultural Research Service, Northwest Center for Small Fruit Research, 3420 \\ NW Orchard Avenue, Corvallis, OR 97330
}

Molecular genetics is a topic that has risen to the forefront in the minds of many scientists and consumers in the past decade. In general, tree and small fruit researchers have been slower to adopt this technology than have scientists working with agronomic crops. Among many issues that have slowed adoption, four are primary.

Critical mass. The fruit research community is fairly small, and those interested in or able to deal with this type of research are a very small subset of this community; thus, advances will be slow in coming and the financial resources devoted to this area will be small.

Poorfinancial return. Aside from strawberries (Fragaria $\times$ ananassa Duchesne), fruit crops are fairly long-lived perennials and their acreage is very small compared with that of agronomic crops. Until recently, the most common way to recoup investment by private or university cultivar development programs was through some sort of royalty from sales of nursery stock. The combination of long life, slow turnover in plantings, and small acreage has led to a very poor return from royalties on plant sales.

Nature of the crops. Most of the fruit crops are perennial, take several years to come into production, and cannot be inbred easily. In addition, many are polyploids. Some of these traits provide good arguments for increased effort in molecular genetics, but they greatly hinder many of the standard mapping and manipulation approaches.

Lack of incentive. Even the crops that have been worked with for many years in modern breeding programs are not very far removed from their "wild" ancestors. Since very large germplasm pools can be tapped for new traits, and these traits can be moved fairly quickly into commercial quality material, there is less incentive to use molecular approaches.

Received for publication 12 June 2000. Accepted for publication 23 Oct. 2000 The cost of publishing this paper was defrayed in part by the payment of page charges. Under postal regulations, this paper therefore must be hereby marked advertisement solely to indicate this fact.

${ }^{1}$ E-mail address: finnc@bcc.orst.edu
Despite these challenges, a solid core of research has developed that should allow the application of molecular genetics to appropriate areas of fruit research.

The papers by Stan Hokanson (2001) and by Ralph Scorza (2001) in this workshop provide excellent overviews of the state of research in molecular genetics in small fruit and tree fruit, respectively. Even though the number of personnel devoted to this kind of research is small, the body of knowledge that is available throughout the world, as reviewed in these articles, is impressive.

The contribution by Jim Luby and Doug Shaw (2001) takes one application of molecular genetics in fruit crops and analyzes it from scientific and economic perspectives. Their conclusions raise some very real concerns about the appropriateness of this technology in fruit crops as currently, broadly applied. Their analyses suggest that we scientists can be as guilty as the next person of hopping on the current, hot, "bandwagon," with but cursory evaluation of the scientific appropriateness and with little, if any, regard for economics.

Hokanson and Scorza's reviews of small fruit and tree fruit research provide a wealth of information that can serve as a reference point as we move forward in fruit molecular genetics. Luby and Shaw provide us an example of how we need to critically analyze new approaches as we make decisions on the most appropriate applications of this knowledge. Scientists who can combine such applications with critical analysis will have the greatest impact in the future.

\section{Literature Cited}

Hokanson, S.C. 2001. SNIps, Chips, BACs, and YACs: Are small fruits in the party mix? HortScience 36:859-871.

Luby, J.J. and D.V. Shaw. 2001. Can marker-assisted selection make dollars and sense in a fruit breeding program? HortScience 36:872-879.

Scorza, R. 2001. Progress in tree fruit improvement through molecular genetics. HortScience 36:855-858. 